\title{
PENGUATAN PENDIDIKAN KARAKTER MELALUI PEMBELAJARAN SEJARAH KEBUDAYAAN ISLAM DI MADRASAH
}

\author{
Ibnu Rusydi \\ Fakultas Agama Islam Universitas Wiralodra \\ E-mail: ibnurs@gmail.com
}

\begin{tabular}{|c|c|c|}
\hline Received & Revised & Accepted \\
\hline 10 Januari 2021 & 10 Februari 2021 & 28 Maret 2021 \\
\hline
\end{tabular}

\section{REINFORCING OF CHARACTER EDUCATION THROUGH LEARNING OF ISLAMIC CIVILIZATION HISTORY IN MADRASAY}

\begin{abstract}
The issues of character education become the hot news in the education world today, including the world of Islamic education in Indonesia. The formation of student character in Islamic educational institutions such as madrasas is a good thing to do. Madrasas play a role in producing students who are smart in science, but also in character and personality. Through the example of Islamic figures and scholars discussed in Islamic Cultural History learning, especially the patience, persistence, and fortitude of the Prophet Muhammad SAW, his companions, scholars, and great figures in Islam so that some characters are built for students such as: honest, disciplined, responsible, independent, social care and hard work.

Keywords: character education, learning, Islamic civilization history, and madrasah

Abstrak

Isu pendidikan karakter menjadi berita yang hangat dibicarakan dalam dunia pendidikan, termasuk di dalamnya dunia pendidikan Islam di Indonesia. Pembentukan karakter siswa di lembaga pendidikan Islam seperti madrasah adalah baik untuk dilakukan. Madrasah berperan dalam mencetak peserta didik yang pintar dalam ilmu pengetahuan, tetapi juga dalam akhlak dan kepribadian. Melalui keteladanan terhadap tokoh Islam dan para ulama yang dibahas dalam pembelajaran Sejarah Kebudayaan Islam, khususnya kesabaran, kegigihan, dan ketabahan dari Nabi Muhammad SAW, para sahabat, para ulama, dan para tokoh besar dalam Islam sehingga terbangun beberapa karakter bagi siswa seperti: religius, jujur, disiplin, bertanggung jawab, mandiri, peduli sosial dan kerja keras.
\end{abstract}

Kata kunci: pendidikan karakter, pembelajaran, sejarah kebudayaan Islam, dan madrasah 


\section{Pendahuluan}

Persoalan umat di Indonesia pada zaman modern semakin kompleks dan dipertontonkan di media televisi dan media sosial, dari kemiskinan, kehidupan ekonomi yang serba sulit, kekerasan, dan kehidupan politik yang banyak dipenuhi dengan hoaks, dan sebagainya. Persoalan itu menjadi tema pembahasan dan diperbincangkan di berbagai media massa, media online, seminar, dan kegiatan lainnya. Persoalan itu misalnya tawuran antar pelajar, bullying di sekolah, kekerasan, dan korupsi yang semakin marak di setiap lini kehidupan, mulai dari tingkat RT di kampung sampai para menteri di kekuasaan pusat. Begitu juga para wakil rakyat dari banyak yang terjerat kasus korupsi. Masyarakat dipertontonkan hal-hal negatif dari para pemimpin yang seharusnya penjadi panutan. Menurut Thomas Lickona, timbulnya berbagai penyakit sosial tersebut bisa jadi karena minimnya perhatian lembaga pendidikan terhadap pendidikan karakter. ${ }^{1}$

Banyak solusi alternatif yang dikemukakan untuk mengatasi persoalan budaya dan karakter bangsa. Pendidikan dianggap sebagai solusi alternatif karena melalui pendidikan akan terbangun generasi bangsa baru yang lebih baik. Sebagai solusi alternatif, pendidikan diharapkan menjadi cara utama meningkatkan kualitas generasi muda yang lebih baik dalam berbagai aspek sehingga dapat mengurangi berbagai dampak buruk dan penyebab berbagai masalah budaya dan budaya dan karakter bangsa. ${ }^{2}$

Persoalan Pendidikan karakter pada dunia pendidikan di Indonesia saat ini menjadi isu penting, termasuk di dalamnya dunia pendidikan Islam di Indonesia dalam memikirkan pembentukan akhlak anak bangsa. Pendidikan karakter diharapkan mampu menjadi landasan dalam menghadapi tantangan kemajuan peradaban Indonesia. Undang Undang No 20 Tahun 2003 Tentang Sistem Pendidikan Nasional pada Pasal 3, menyebutkan bahwa Pendidikan Nasional berfungsi mengembangkan kemampuan dan membentuk karakter serta peradaban bangsa yang bermartabat dalam rangka mencerdaskan kehidupan bangsa. Ini berarti pendidikan nasional bertujuan mengembangkan potensi peserta didik agar menjadi manusia yang beriman dan bertakwa kepada Tuhan Yang Maha Esa, berakhlak mulia, sehat, berilmu, cakap, kreatif, mandiri, dan menjadi warga negara yang demokratis serta bertanggung jawab.

Pembentukan karakter siswa madrasah adalah hal penting yang harus segera dilakukan. Bahkan, kalau kita berbicara masa mendatang, peran madrasah bukan hanya dalam mendidik anak yang pintar dalam ilmu pengetahuan, tetapi juga dalam akhlak dan kepribadian. Pendidikan karakter terkadang dimaknakan sebagai

\footnotetext{
${ }^{1}$ Thomas Lickona, "Pendidikan Karakter Panduan Lengkap Mendidik Siswa Menjadi Pintar Dan Baik," 2013.

${ }^{2}$ Tim, Pengembangan Pendidikan Budaya dan Karakter Bangsa: Pedoman Sekolah, Kementerian Pendidikan Nasional, Badan Penelitian dan Pengembangan, Pusat Kurikulum Tahun 2010
} 
pendidikan akhlak, ini berarti pendidikan akhlak adalah pendidikan karakter yang tidak dapat dipisahkan dari pendidikan agama. ${ }^{3}$

Makna pendidikan pada umumnya diartikan sebagai belajar dan mengajar. Pendidikan juga bermakna mengangkat dan menegakkan martabat manusia melalui tansmisi yang dimilikinya, terutama dalam bentuk berbagi pengetahuan (transfer of knowledge) dan berbagi nilai kebajikan (transfer of values). ${ }^{4}$ Ini berarti pendidikan tidak hanya membekali siswa dengan ilmu pengetahun semata, tetapi juga dengan pendidikan Akhlak dimana peran ini diberikan kepada lembaga Pendidikan Agama. Madrasah Ibtidaiyah, Tsanawiyah, dan Aliyah merupakan lembaga pendidikan formal dilingkungan Kementerian Agama yang pelajaran keagamaannnya lebih dominan dibandingkan sekolah umum. Di antara materi Pendidikan Agama Islam (PAI) tersebut adalah materi pelajaran Sejarah Kebudayaan Islam (SKI). Pembelajaran SKI di Madrasah Ibtidaiyah sebagai bagian yang integral dari Pendidikan Agama.

Kalau di sekolah umum seperti SD, SMP, dan SMA, materi pembelajaran Sejarah Kebudayaan Islam (SKI) bersifat umum dan masuk bagian dari lingkup materi Pendidikan Agama Islam. Meskipun demikian mata pelajaran SKI memiliki kontribusi dalam pembentukan karakter siswa melalui materi cerita keteladanan para tokoh tokoh muslim, khususnya meneladani prilaku dan ucapan Nabi Muhammad SAW. Nilai pendidikan karakter dalam materi pembelajaran SKi terlihat dalam keteladanan dakwah Nabi Muhammad dan para sahabat yang meliputi kegigihan, kesabaran, dan ketabahan.

Sebetulnya upaya penguatan pendidikan karakter dalam dunia pendidikan Islam di Indonesia bukanlah suatu hal baru, karena sudah menjadi program Pemerintah sejak tahun 2010 dalam penguatan pendidikan karakter di sekolah dan menjadi Gerakan Nasional. Sudah banyak penelitian yang mengkaji tentang peran dan pentingnya pendidikan karakter bagi dunia pendidikan serta implementasi pendidikan karakter secara langsung dan pengembangannya di sekolah. Dengan kajian ini diharapkan proses pembudayaan nilai nilai karakter terus berjalan dan berkesinambungan di dunia pendidikan Islam. Ini berarti lembaga pendidikan Islam, tidak hanya meningkatkan kualitas akademik siswa semata, tetapi juga bertanggungjawab atas pembentukan akhlak mulia. Terkadang idealitas pembentukan karakter ini terkesampingkan dengan tuntutan ekonomi dan politik pendidikan. ${ }^{5}$

\section{Metode Penelitian}

\footnotetext{
${ }^{3}$ N Nurjannah and Nurhayati Ode Aci, "Implementasi Pendidikan Karakter Dalam Pembelajaran Sejarah Kebudayaan Islam Di Madrasah Ibtidaiyah,” Foramadiahi, 2019, http://journal.iainternate.ac.id/index.php/foramadiahi/article/view/144.

${ }^{4}$ Arifuddin Arif, "Pengantar Ilmu Pendidikan Islam, Jakarta” (Kultura GP Press Group, 2008).

${ }^{5}$ Agus Wibowo, "Manajemen Pendidikan Karakter Di Sekolah (Konsep Dan Praktik Implementasi) / Agus Wibowo," 2013.
} 
Penelitian ini menggunakan pendekatan kualitatif dengan jenis studi pustaka (library reseach). Penelitian ini dilakukan dengan cara melakukan perbandingan terhadap berbagai hasil penelitian yang berkaitan dengan penguatan pendidikan karakter melalui pembelajaran sejarah yang dilakukan dalam kegiatan pembelajaran sehari-hari.

\section{Hasil dan Pembahasan Pendidikan karakter}

Berkaitan dengan pendidikan karakter, dalam kamus Bahasa Indonesia kata "karakter" diartikan sebagai tabiat, sifat-sifat kejiwaan, akhlak, budi pekerti, watak, yang membedakan seseorang dengan yang lain. Faridah Alawiyah memaknai karakter sebagai indentitas yang menjadi nilai dasar dan ciri khas setiap individu yang menjadi dasar dalam berpikir dan bertingkah laku kepada Tuhannya, kepada diri-sendiri, kepada sesamanya, dan kepada lingkungannya, yang kemudian tercermin dalam sebuah perilaku. Upaya untuk membentuk individu berkarakter dilakukan melalui pendidikan karakter yang merupakan upaya sadar untuk menjadikan setiap individu memiliki karakter tersebut. ${ }^{6}$

Megawangi memaknai kata karakter berasal dari kata Yunani "Charassein" yang berarti mengukir sehingga terbentuk sebuah pola. Mempunyai akhlak dan budi pekerti yang baik dilakukan melalui proses, dan tidak secara otomatis dimiliki manusia begitu dilahirkan, tetapi memerlukan waktu dan proses panjang dengan cara pengasuhan dan pendidikan (proses pengukiran)". ${ }^{7}$ Pendidikan karakter dapat juga berarti pendidikan budi pekerti atau pendidikan akhlak. Lickona mengartikan pendidikan karakter sebagai upaya secara sadar untuk memperbaiki karakter pada peserta didik. ${ }^{8}$ Sedangkan Agus Wibowo mendefinisikan pendidikan karakter dengan pendidikan yang menanamkan dan mengembangkan karakter luhur kepada anak didik, yang kemudian karakter tersebut dipraktekkan dalam kehidupannya baik di keluarga, masyarakat, dan negara. ${ }^{9}$

Ratna Megawangi memandang pentingnya pendidikan karakter. Karakter merupakan hal dasar dalam berbangsa dan bernegara, karakter berperan sebagai kemudi bangsa, dan karaker harus dibangun dan dibentuk agar menjadi negara yang bermartabat. ${ }^{10}$ Untuk itu lembaga pendidikan baik itu umum atau madrasah wajib meningkatkan mutu akademik siswa dan karakternya.

${ }^{6}$ Faridah Alawiyah, "Kebijakan Dan Pengembangan Pembangunan Karakter Melalui Pendidikan Di Indonesia,” Aspirasi: Jurnal Masalah-Masalah Sosial 3, no. 1 (2012): 87-101.

7 Ratna Megawangi, Pendidikan \{Karakter\} \{Solusi\} \{Tepat\} \{Untuk\} \{Membangun\}, Jakarta: Indonesia Herritage Foundation, 2004.

\footnotetext{
${ }^{8}$ Lickona, "Pendidikan Karakter Panduan Lengkap Mendidik Siswa Menjadi Pintar Dan Baik."

${ }^{9}$ Wibowo, "Manajemen Pendidikan Karakter Di Sekolah (Konsep Dan Praktik Implementasi) / Agus Wibowo."

${ }^{10}$ Megawangi Ratna, "Pendidikan Karakter: Solusi Tepat Untuk Membangun Bangsa," Bogor: Heritage Foundation, 2004.
} 
Dalam pendidikan karakter yang dilaksanakan di Indonesia terdapat 18 nilai pendidikan karakter yang tergambar dalam tabel berikut: ${ }^{11}$

Tabel. 2.1

Nilai dan deskripsi nilai pendidikan budaya dan karakter bangsa

\begin{tabular}{|c|c|}
\hline Nilai & Deskripsi \\
\hline 1. Religius & $\begin{array}{l}\text { Perilaku yang didasarkan pada upaya menjadikan dirinya sebagai } \\
\text { orang yang selalu dapat dipercaya dalam perkataan, tindakan, dan } \\
\text { pekerjaan. }\end{array}$ \\
\hline 2. Toleransi & $\begin{array}{l}\text { Sikap dan tindakan yang menghargai perbedaan agama, suku, } \\
\text { etnis,pendapat, sikap dan tindakan orang lain yang berbeda dari } \\
\text { dirinya }\end{array}$ \\
\hline 3. Jujur & $\begin{array}{l}\text { Perilaku yang didasarkan pada upaya menjadikan dirinya sebagai } \\
\text { orang yang selalu dapat dipercaya dalam perkataan, tindakan, } \\
\text { dan pekerjaan }\end{array}$ \\
\hline 4. Disiplin & $\begin{array}{l}\text { Tindakan yang menunjukkan perilaku tertib dan patuh pada } \\
\text { berbagai ketentuan dan peraturan }\end{array}$ \\
\hline 5. Kerja keras & $\begin{array}{l}\text { Perilaku yang menunjukkan upaya sungguh-sungguh dalam } \\
\text { mengatasi berbagai hambatan belajar dan tugas serta menyelesaikan } \\
\text { tugas dengan sebaik-baiknya }\end{array}$ \\
\hline 6. Kreatif & $\begin{array}{l}\text { Berpikir dan melakukan sesuatu yang menghasilkan cara atau } \\
\text { hasil baru berdasarkan apa yang telah dimiliki }\end{array}$ \\
\hline 7. Mandiri & $\begin{array}{l}\text { Sikap dan prilaku yang tidak mudah tergantung pada orang lain } \\
\text { dalam menyelesaikan tugas-tugas }\end{array}$ \\
\hline 8. Demokratis & $\begin{array}{l}\text { cara berfikir, bersikap dan bertindak yang menilai sama hak dan } \\
\text { kewajiban dirinya dan orang lain }\end{array}$ \\
\hline 9. Rasa Ingin Tahu & $\begin{array}{l}\text { sikap dan tindakan yang selalu berupaya untuk mengetahui lebih } \\
\text { mendalam dan meluas dari apa yang dipelajarinya, dilihat, dan } \\
\text { didengar }\end{array}$ \\
\hline $\begin{array}{l}\text { 10. Semangat } \\
\text { Kebangsaan }\end{array}$ & $\begin{array}{l}\text { cara berpikir, bertindak, dan wawasan yang menempatkan } \\
\text { kepentingan bangsa dan negara di atas kepentingan diri dan } \\
\text { kelompoknya }\end{array}$ \\
\hline 11. Cinta Tanah Air & $\begin{array}{l}\text { Cara berfikir, bersikap dan berbuat yang menunjukkan kesetiaan, } \\
\text { kepedulian, dan penghargaan yang tinggi terhadap bahasa, } \\
\text { lingkungan fisik, sosial, budaya, ekonomi, dan politik } \\
\text { bangsanya. } \\
\text { Cara berfikir, bersikap dan berbuat yang menunjukkan kesetiaan, } \\
\text { kepedulian, dan penghargaan yang tinggi terhadap bahasa, } \\
\text { lingkungan fisik, sosial, budaya, ekonomi, dan politik } \\
\text { bangsanya. }\end{array}$ \\
\hline 12. Menghargai Prestasi & $\begin{array}{l}\text { Sikap dan tindakan yang mendorong dirinya untuk menghasilkan } \\
\text { sesuatu yang berguna bagi masyarakat, dan mengakui dan } \\
\text { menghormati keberhasilan orang lain. }\end{array}$ \\
\hline $\begin{array}{l}\text { 13. } \\
\text { Bersahabat/Komunikat } \\
\text { if }\end{array}$ & $\begin{array}{l}\text { Tindakan yang memperlihatkan rasa senang berbicara, bergaul, } \\
\text { dan bekerjasama dengan orang lain. }\end{array}$ \\
\hline 14. Cinta Damai & Sikap, perkataan dan tindakan yang menyebabkan orang lain \\
\hline
\end{tabular}

${ }^{11}$ Zubaedi, Desain Pendidikan Karakter Zubaedi, "Konsepsi Dan Aplikasinya Dalam Lembaga Pendidikan,”Jakarta: Kencana, 2011. 
Ibnu Rusydi

Penguatan Pendidikan Karakter melalui......

\begin{tabular}{|l|l|}
\hline 15. Senang Membaca & merasa senang dan aman atas kehadiran dirinya \\
\hline 16. Peduli Sosial & $\begin{array}{l}\text { Kebiasaan menyediakan waktu untuk membaca berbagai bacaan } \\
\text { yang memberikan kebajikan bagi dirinya. }\end{array}$ \\
\hline 17. Peduli Lingkungan & $\begin{array}{l}\text { sikap dan tindakan yang selalu ingin memberi bantuan kepada } \\
\text { orang lain dan masyarakat yang membutuhkan }\end{array}$ \\
\hline $\begin{array}{l}\text { Sikap dan tindakan yang selalu berupaya mencegah kerusakan } \\
\text { lingkungan alam di sekitarnya, dan mengembangkan upayaupaya } \\
\text { untuk memperbaiki kerusakan alam yang sudah terjadi. }\end{array}$ \\
\hline 18. Tanggung Jawab & $\begin{array}{l}\text { Sikap dan perilaku seseorang untuk melaksanakan tugas dan } \\
\text { kewajibannya, yang seharusnya dia lakukan, terhadap diri } \\
\text { sendiri, masyarakat, lingkungan (alam, sosial dan budaya), } \\
\text { negara dan Tuhan YME }\end{array}$ \\
\hline
\end{tabular}

\section{Nilai-nilai Karakter dalam Pembelajaran SKI}

Dalam dunia pendidikan Islam khususnya di madrasah, wahana pembinaan dan pengembangan karakter yang dilakukan menggunakan pendekatan terintegrasi dalam semua mata pelajaran, kegiatan kokurikuler dan ekstrakurikuler, serta pembiasaan perilaku. Dengan demikian, pendidikan karakter tidak hanya dilakukan dengan pemberian materi khusus karakter, tetapi dikembangkan menjadi terintegrasi dalam kurikulum secara komprehensif. Perencanaan pendidikan karakter di madrasah mengacu pada visi yang telah ditetapkan. Dengan visi yang jelas dan tertulis, seluruh personil madrasah memahami dan mengerti kemana arah pengembangan pendidikan karakter yang ditetapkan. Pendidikan karakter akan berhasil apabila disertai contoh dan pembiasan dari semua personil sekolah, dari kepala sekolah, guru, tata usaha, siswa, orang, dan masyarakat.

Pembelajaran adalah kegiatan belajar mengajar. Suharsimi Arikunto menjelaskan bahwa Pembelajaran adalah kegiatan yang mengandung terjadinya proses penguasaan pengetahuan, keterampilan, dan sikap oleh subyek yang sedang belajar. Pembelajaran adalah bantuan pendidikan kepada siswa agar mencapai kedewasaan dibidang pengetahuan, keterampilan, dan sikap. ${ }^{12}$

Materi Pendidikan agama Islam di Madrasah Ibtidaiyah maupun Madrasah Tsanawiyah meliputi Sejarah Kebudayaan Islam, Al-Quran Hadits, Aqidah Akhlak, Fiqih, dan bahasa Arab.. Mata pelajaran Sejarah Kebudayaan Islam merupakan bagian dari materi PAI pada Madrasah untuk mengarahkan pemahaman dan pengembangan kemampuan dasar siswa dalam menghayati perjalanan Sejarah Kebudayaan Islam dalam mewujudkan nilai-nilai iman dan takwa kepada Allah SWT sesuai dengan ketentuan al Qur'an dan Hadits. ${ }^{13}$ Ini berarti bawa substansi pembelajaran Sejarah Kebudayaan Islam di madrasah bisa berarti menanamkan

${ }^{12}$ Suharsimi Arikunto, “Dasar-Dasar Evaluasi Pendidikan Edisi 2,” Jakarta: Bumi Aksara, 2012.

13 Nurjanah and Nurhayati Ode Aci, "Implementasi Pendidikan Karakter Dalam Pembelajaran Sejarah Kebudayaan Islam Di Madrasah Ibtidaiyah.” Foramadiahi: Jurnal Kajian Pendidikan Keislaman Volume: 11 Nomor: 1 
nilai-nilai karakter keislaman, menanamkan nilai-nilai kejujuran, keadilan, solidaritas, toleransi, disiplin, tanggungjawab dan konsistensi. ${ }^{14}$

Sejarah Kebudayaan Islam (SKI) merupakan mata pelajaran yang mengkaji sejarah, dan perkembangan peradaban Islam dan para tokohnya yang berprestasi dalam lintasan sejarah Islam dimasa lalu. Kajian Sejarah Kebudayaan Islam dimulai dari kondisi bangsa Arab sebelum Islam, sejarah Nabi Muhammad SAW di Makkah dan Madinah, masa Khulafaurrasydin, masa Bani Umayyah, bani Abbasiyah, ke Khalifahan Turki Usmani, dan kondisi umat Islam masa modern.

Secara prinsip materi pelajaran Sejarah Kebudayan Islam memiliki tujuan supaya peserta didik mengenal, memahami, menghayati, dan meneladani sosok Nabi Muhammad SAW beserta keluarganya, para sahabatnya, para tokoh-tokoh Islam yang berprestasi, dan para ulama besar untuk diteladani, diambil hikmah kebaikan dalam pembiasaan kepribadian peserta didik.

Melalui pembelajaran Sejarah Kebudayaan Islam siswa menjadi mengerti bahwa para ulama terdahulu adalah orang orang yang alim dan akhlaknya baik. Ini akan merefleksikan pada diri siswa bahwa seorang yang belajar ilmu agama di lembaga pendidikan Islam harus menampilkan dalam kehidupan sehari-hari sikap dan perilaku sebagai ciri khas seorang siswa madrasah yang baik. Sikap sopan santun baik di madrasah maupun di rumah. Melalui pembelajaran sejarah Islam, para siswa diharapkan meneladani karakter para ulama sehingga bisa menjadi "model yang diikuti" dalam bertindak dan berprlaku sehari-hari dan menjadi pondasi yang kuat dalam pembentukan karakter di era modern ini.

Saat ini materi pembelajaran sejarah kebudayaan Islam di madrasah pada umumnya disampaikan secara sederhana dan lebih pada pengajaran dengan cara ceramah. Hal tersebut yang membuat siswa justru menjadi pasif dan kurang bisa mengeksplor kemampuannya. Keterbatasan sarana dan media belajar di madrasah menjadi salah satu faktor rendahnya kemampuan kognitif dan sikap. Untuk itu perlu pembelajaran sejarah Kebudayaan Islam yang menyenangkan. Penguasaan materi dan penggunaan media oleh guru akan sangat membantu mereka untuk menerima pengetahuan.

Mata pelajaran Sejarah Kebudayaan Islam di madrasah bertujuan agar peserta didik memiliki kemampuan-kemampuan sebagai berikut:

a. Memberikan pengetahuan tentang sejarah Agama Islam dan kebudayaan Islam pada masa Nabi Muhammad Saw dan Khulafaturrasyidin kepada siswa agar ia memiliki konsep yang obyektif dan sistematis dan perspektif historis.

b. Mengambil ibrah/hikmah, nilai dan makna yang terdapat dalam sejarah

c. Menanamkan penghayatan dan kemauan yang kuat untuk mengamalkan akhlak yang baik dan menjauhi akhlak yang buruk berdasarkan cematnya atas fakta sejarah yang ada.

d. Membekali siswa untuk membentuk kepribadiannya berdasarkan tokoh-tokoh teladan sehingga terbentuk kepribadian yang luhur. Membangun kesadaran peserta didik tentang pentingnya mempelajari landasan ajaran, nilai-nilai dan

${ }^{14}$ Darmaningtyas \& J. Sumardianta, Ironi dan Anomali HAM di Dunia Pendidikan, dalam Wacana Edisi 8. Tahun II 2001, h. 211 
norma-norma Islam yang telah dibangun oleh Rasulullah saw dalam rangka mengembangkan kebudayaan dan peradapan Islam.

e. Membangun kesadaran peserta didik tentang pentingnya waktu dan tempat yang merupakan sebuah proses dari masa lampau, masa kini dan masa depan.

f. Melatih daya kritis peserta didik untuk memahami fakta sejarah secara benar dengan didasarkan pada pendekatan ilmiah.

g. Menumbuhkan apresiasi dan penghargaan peserta didik terhadap peninggalan sejarah Islam sebagai bukti peradaban umat Islam di masa lampau.

h. Mengembangkan kemampuan peserta didik dalam mengambil keputusan ibrah dari peristiwa-pristiwa bersejarah (Islam), meneladani tokoh-tokoh berprestasi, dan mengaitkannya dengan kegiatan sosial, budaya, politik, ekonomi, iptek dan seni, serta mengembangkan kebudayaan dan peradapan Islam. ${ }^{15}$

Peran guru sangat penting untuk membentuk karakter siswa. Guru menjadi teladan yang tingkah laku dan perkataaanya setiap hari dilihat siswa. Cara berpakaian, termasuk amaliyah ibadah seorang guru akan menjadi contoh siswa, karena guru merupakan contoh kongkrit dari pembentukan karakter di madrasah. Oleh karena itu, pembentukan karakter dilakukan terus menerus melalui penanaman karakter yang baik dan diaplikasikan dengan tindakan yang dilakukan oleh semua pihak di madrasah. ${ }^{16}$

\section{Simpulan}

Pengembangan pendidikan karakter siswa dilakukan melalui kegiatan proses belajar mengajar mata pelajaran Sejarah Kebudayaan Islam. Melalui keteladanan terhadap tokoh yang dibahas dalam materi pembelajaran, khususnya keteladanan dari Nabi Muhammad SAW, para sahabat, para ulama, dan para tokoh besar dalam Islam sehingga terbangun beberapa karakter seperti: religius, jujur, bertanggung jawab, mandiri, peduli sosial dan kerja keras. Karakter-karakter tersebut diteladani dan menjadi landasan siswa dalam berkehidupan di dunia modern ini.

Melalui pembelajaran sejarah Kebudayaan Islam, siswa mendapatkan ibrah yang berarti pelajaran. Artinya ketika siswa mempelajari materi pembelajaran, ia akan mendapatkan pelajaran berharga dari materi tersebut. Setelah mempelajari materi pelajaran siswa menemukan pelajaran baik untuk dapat diaplikasikan dalam kehidupan sehari-hari, baik dalam aspek spiritual dan sosial. Nilai pendidikan karakter dalam pembelajaran Sejarah Kebudayaan Islam terlihat jelas misalnya dalam keteladanan dakwah Nabi Muhammad dan para sahabat yang meliputi kegigihan, kesabaran, dan ketabahan.

\footnotetext{
${ }^{15}$ Dikutip dari Kurikulum Sejarah Kebudayaan Islam MI, MTs, dan MA berdasarkan Peraturan Mentri Agama RI No 2 tahun 2008 tentang Standar Isi dan Standar Kompetensi Lulusan PAI

${ }^{16}$ Tutuk Ningsih, "Peran Pendidikan Islam Dalam Membentuk Karakter Siswa Di Era Revolosi Industri 4.0 Di Madrasah Tsanawiyah Negeri 1 Banyumas," INSANIA: Jurnal Pemikiran Alternatif Kependidikan 24, no. 2 (2019): 220-31.
} 


\section{DAFTAR PUSTAKA}

Alawiyah, Faridah. "Kebijakan Dan Pengembangan Pembangunan Karakter Melalui Pendidikan Di Indonesia." Aspirasi: Jurnal Masalah-Masalah Sosial 3, no. 1 (2012): 87-101.

Arif, Arifuddin. "Pengantar Ilmu Pendidikan Islam, Jakarta." Kultura GP Press Group, 2008.

Arikunto, Suharsimi. "Dasar-Dasar Evaluasi Pendidikan Edisi 2." Jakarta: Bumi Aksara, 2012.

Lickona, Thomas. "Pendidikan Karakter Panduan Lengkap Mendidik Siswa Menjadi Pintar Dan Baik," 2013.

Megawangi, Ratna. Pendidikan \{Karakter\} \{Solusi\} \{Tepat\}\{Untuk\}\{Membangun\}. Jakarta: Indonesia Herritage Foundation, 2004.

Ningsih, Tutuk. "Peran Pendidikan Islam Dalam Membentuk Karakter Siswa Di Era Revolosi Industri 4.o Di Madrasah Tsanawiyah Negeri 1 Banyumas." INSANIA: Jurnal Pemikiran Alternatif Kependidikan 24, no. 2 (2019): 220-31.

Nurjannah, Nurhayati Ode Aci. "Implementasi Pendidikan Karakter Dalam Pembelajaran Sejarah Kebudayaan Islam Di Madrasah Ibtidaiyah.” Foramadiahi, 2019. http://journal.iain-ternate.ac.id/index.php/foramadiahi/article/view/144.

Ratna, Megawangi. "Pendidikan Karakter: Solusi Tepat Untuk Membangun Bangsa." Bogor: Heritage Foundation, 2004.

Wibowo, Agus. "Manajemen Pendidikan Karakter Di Sekolah (Konsep Dan Praktik Implementasi) / Agus Wibowo," 2013.

Zubaedi, Desain Pendidikan Karakter. "Konsepsi Dan Aplikasinya Dalam Lembaga Pendidikan." Jakarta: Kencana, 2011. 